\title{
Rancang Bangun Aplikasi Pemantauan Trafik Lalu Lintas Menggunakan GPS Smartphone
}

\author{
Nofli K. Staal, Steven R. Sentinuwo, Alwin M. Sambul \\ Teknik Informatika Universitas Sam Ratulangi. Manado, Indonesia \\ justfly028@gmail.com, steven@unsrat.ac.id, asambul@unsrat.ac.id
}

\begin{abstract}
Abstrak - Tingkat pertumbuhan pengguna jalan di kota manado berkembang begitu cepat antara lain pengguna jalan kaki, dengan demikian saat ini terjadi berbagai penumpukan kendaraan di beberapa titik kota manado yang menyebabkan kemacetan. Rancang Bangun Aplikasi Pemantauan Trafik Lalu Lintas Menggunakan GPS Smartphone memberikan informasi bagi pengguna jalan kota manado dimana setiap posisi Longtitude dan Latitude setiap smartphone yang menginstal aplikasi tersebut secara otomatis terkirim ke server kemudian diolah oleh sistem yang natinya diketahui secara realtime titiktitik jalan mana yang terjadi penumpukan kendaraan. Dalam pengembangan aplikasi ini menggunakan metode pengembangan sistem RAD (Rapid Aplication Development) dan menggunakan Android Studio dalam pembuatan aplikasinya.
\end{abstract}

Kata Kunci : Aplikasi, Trafick, RAD, Smarthphone, Lalu-lintas, GPS, Longitude, Latitude, Fase.

\section{PENDAHULUAN}

Transportasi merupakan sarana yang sangat penting dalam menunjang kegiatan perekonomian masyarakat di Indonesia. Transportasi yang ada saat ini digunakan untuk mendukung laju pertumbuhan ekonomi sehingga dapat menjadi penggerak dinamika pembangunan. Aktivitas penduduk yang sangat tinggi, menyebabkan perkembangan transportasi meningkat sehingga pergerakan lalu lintas menjadi sangat padat. Dampak dari pergerakan lalu lintas adalah kemacetan jalan. Kemacetan adalah padatnya jalur atau jalan raya yang mengakibatkan lambatnya kecepatan normal kendaraan karena adanya berbagai halangan mengakibatkan kendaraan berdekatan di jalan. ${ }^{[1]}$

Menurut Azhar Aris (2012) terdapat 7 penyebab kemacetan, yaitu physical bottlenecks (kemacetan fisik), kecelakaan lalu lintas (traffic incident), area pekerjaan (work zone), cuaca buruk (bad weather), alat pengatur lalu lintas yang kurang memadai (poor signal timing), acara khusus (special event), dan fluktuasi pada arus normal (fluctuations in normal traffic). ${ }^{[2]}$

Terjadinya kemacetan di berbagai tempat mengakibatkan setiap pengendara yang memiliki aktivitas berbeda-beda sering terjebak dalam kemacetan, maka mobilitas para pengendara juga mengalami gangguan. Gangguan-gangguan ini akan berdampak negative, seperti kesulitan dalam mengatur waktu yang mengakibatkan menghabiskan waktu berjam-jam dalam berkendara.

Agar tidak terjebak pada kemacetan, diperlukan pemantauan trafik lalu lintas, berupa Aplikasi mobile yang memanfaatkan GPS pada Smartphone.

Perkembangan teknologi mobile semakin menarik banyak peminat untuk pemanfaatannya. Contoh nyatanya adalah pertumbuhan pemakai smartphone di Indonesia. Smartphone memiliki ciri khas yakni memiliki sistem operasi di dalamnya yang memungkinkan penggunanya untuk menggunakan berbagai aplikasi dan fitur-fitur yang mendukung penggunanya. Salah satu fitur yang terdapat pada smartphone adalah Global Possitioning System (GPS). GPS memungkinkan penggunanya mengetahui letak geografis baik segi lintang maupun bujur. GPS dan tracking juga dapat membantu pengguna smartphone untuk mencari jalan atau tempat yang hendak dituju. Fitur tersebut dikenalkan juga oleh Google melalui Google Maps. Pengguna smartphone yang mengaktifkan fitur GPSnya dapat mengoptimalkan pemakaian Google Maps sehingga dapat menampilkan posisinya secara real-time pada map yang ditampilkan pada Google Maps.

Untuk itu telepon genggam android saat ini merupakan pilihan yang tepat untuk memantau trafik lalu lintas. Oleh karena itu dilakukan penelitian dengan judul "Rancang Bangun Aplikasi Pemantauan Trafik Lalu Lintas Menggunakan GPS Smartphone", harapan dilakukan penelitian ini adalah menggunakan potensi yang dimiliki oleh telepon genggam Smartphone yang biasa digunakan oleh para pengendara kendaran untuk berkomunikasi saat dalam perjalanan, dan dapat juga membantu mengetahui keadaan trafik lalu lintas jalan. 


\section{LANDASAN TEORI}

A. Lalu Lintas

Lalu lintas di dalam Undang-undang No 22 tahun 2009 didefinisikan sebagai gerak Kendaraan dan orang di Ruang Lalu Lintas Jalan, sedang yang dimaksud dengan Ruang Lalu Lintas Jalan adalah prasarana yang diperuntukkan bagi gerak pindah Kendaraan, orang, dan atau barang yang berupa Jalan dan fasilitas pendukung.

Ada tiga komponen terjadinya lalu lintas seperti pada gambar 1, yaitu manusia sebagai pengguna, kendaraan dan dalan yang saling berinteraksi dalam pergerakan kendaraan yang memenuhi persyaratan kelaikan dikemudikan oleh pengemudi mengikuti aturan lalu lintas yang ditetapkan berdasarkan peraturan perundangan yang menyangkut lalu lintas dan angkutan jalan melalui jalan yang memenuhi persyaratan geometrik.

- Manusia Sebagai Pengguna

Manusia sebagai pengguna dapat berperan sebagai pengemudi atau pejalan kaki yang dalam keadaan normal mempunyai kemampuan dan kesiagaan yang berbeda-beda (waktu reaksi, konsentrasi dll).

- Kendaraan

Kendaraan digunakan oleh pengemudi mempunyai karakteristik yang berkaitan dengan kecepatan, percepatan, perlambatan, dimensi dan muatan yang membutuhkan ruang lalu lintas yang secukupnya untuk bisa bermanuver dalam lalu lintas.

- Jalan

Jalan merupakan lintasan yang direncanakan untuk dilalui kendaraan bermotor maupun kendaraan tidak bermotor termasuk pejalan kaki

\section{Manusia}
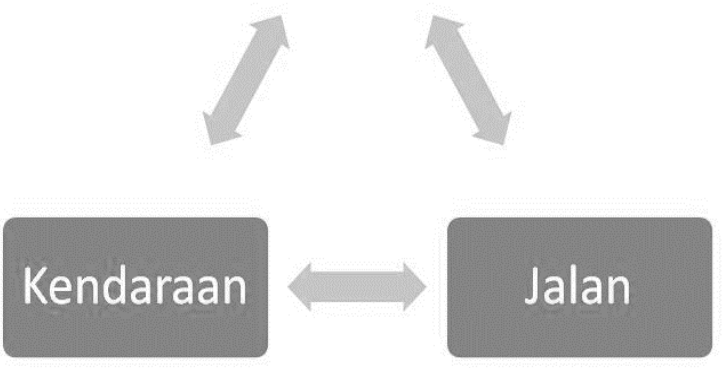

Gambar 1. Komponen Lalu Lintas
B. Android Studio

Android Studio adalah Lingkungan Pengembangan Terpadu - Integrated Development Environment (IDE) untuk pengembangan aplikasi Android, berdasarkan IntelliJ IDEA . Selain merupakan editor kode IntelliJ dan alat pengembang yang berdaya guna, Android Studio menawarkan fitur lebih banyak untuk meningkatkan produktivitas Anda saat membuat aplikasi Android, misalnya:

- Sistem versi berbasis Gradle yang fleksibel

- Emulator yang cepat dan kaya fitur

- Lingkungan yang menyatu untuk pengembangan bagi semua perangkat Android

- Instant Run untuk mendorong perubahan ke aplikasi yang berjalan tanpa membuat APK baru

- Template kode dan integrasi GitHub untuk membuat fitur aplikasi yang sama dan mengimpor kode contoh

- Alat pengujian dan kerangka kerja yang ekstensif

- Alat Lint untuk meningkatkan kinerja, kegunaan, kompatibilitas versi, dan masalah-masalah lain

- Dukungan $\mathrm{C}++$ dan NDK

- Dukungan bawaan untuk Google Cloud Platform, mempermudah pengintegrasian Google Cloud Messaging dan App Engine

Setiap proyek di Android Studio berisi satu atau beberapa modul dengan file kode sumber dan file sumber daya. Jenis-jenis modul mencakup:

- Modul aplikasi Android

- Modul Pustaka

- Modul Google App Engine

Secara default, Android Studio akan menampilkan file proyek Anda dalam tampilan proyek Android. Tampilan disusun berdasarkan modul untuk memberikan akses cepat ke file sumber utama proyek Anda.

Semua file versi terlihat di bagian atas di bawah Gradle Scripts dan masing-masing modul aplikasi berisi folder berikut:

- manifests: Berisi file AndroidManifest.xml.

- java: Berisi file kode sumber Java, termasuk kode pengujian JUnit.

- res: Berisi semua sumber daya bukan kode, seperti tata letak XML, string UI, dan gambar bitmap.

Struktur proyek Android pada disk berbeda dari representasi rata ini. Untuk melihat struktur file sebenarnya dari proyek ini, pilih Project dari menu tarik turun Project .

Anda juga bisa menyesuaikan tampilan file proyek untuk berfokus pada aspek tertentu dari pengembangan aplikasi Anda. Misalnya, memilih tampilan Problems dari tampilan proyek Anda akan menampilkan tautan ke file sumber yang berisi 
kesalahan pengkodean dan sintaks yang dikenal, misalnya tag penutup elemen XML tidak ada dalam file tata letak. ${ }^{[4]-[5]}$

\section{LBS (Location Based Service)}

Layanan Berbasis Lokasi adalah layanan informasi yang dapat diakses melalui mobile divice dengan menggunakan mobile network, yang dilengkapi kemampuan untuk memanfaatkan lokasi dari mobile device tersebut. LBS memberikan kemungkinan komunikasi dan interaksi dua arah.

Oleh karena itu pengguna memberi tahu penyedia layanan untuk mendapatkan informasi yang dia butuhkan, dengan refrensi posisi pengguna tersebut. Layanan berbasis lokasi dapat digambarkan sebagai suatu layanan yang berada pada pertemuan tiga teknologi yaitu: Geographic Information System, Internet Service, dan Mobile Device, hal ini dapat dilihat pada gambar LBS adalah pertemuan dari 3 Teknologi. ${ }^{[6]}$

\section{Global Positioning System (GPS)}

GPS (Global Positioning System) adalah sistem satelit navigasi dan pementuan posisi yang dimiliki dan dikelola oleh Amerika Serikat. Sistem ini didesain untuk memberikan posisi dan kecepatan tiga-dimensi serta informasi mengenai waktu, secara kontinyu di seluruh dunia tanpa bergantung waktu dan cuaca, bagi banyak orang secara simultan. Saat ini GPS sudah banyak digunakan orang di seluruh dunia dalam berbagai bidang aplikasi yang menuntut informasi tentang posisi, kecepatan, percepatan ataupun waktu yang teliti. GPS dapat memberikan informasi posisi dengan ketelitian bervariasi dari beberapa millimeter (orde nol) sampai dengan puluhan meter.

Beberapa kemampuan GPS antara lain dapat memberikan informasi tentang posisi, kecepatan, dan waktu secara cepat, akurat, murah, dimana saja di bumi ini tanpa tergantung cuaca. Hal yang perlu dicatat bahwa GPS adalah satu-satunya sistem navigasi ataupun sistem penentuan posisi dalam beberapa abad ini yang memiliki kemampuan handal seperti itu. Ketelitian dari GPS dapat mencapai beberapa mm untuk ketelitian posisinya, beberapa $\mathrm{cm} / \mathrm{s}$ untuk ketelitian kecepatannya dan beberapa nanodetik untuk ketelitian waktunya. Ketelitian posisi yang diperoleh akan tergantung pada beberapa faktor yaitu metode penentuan posisi, geometri satelit, tingkat ketelitian data, dan metode pengolahan datanya. ${ }^{[7]}$

\section{METODOLOGI PENELITIAN}

Adapun metode pengembangan sistem yang digunakan pada penelitian ini yaitu metode Rapid Application Development (RAD). Rapid Application
Development (RAD) adalah salah satu metode pengembangan suatu sistem informasi dengan waktu yang relatif singkat. Untuk pengembangan suatu sistem informasi yang normal membutuhkan waktu minimal 180 hari, akan tetapi dengan menggunakan metode RAD suatu sistem dapat diselesaikan hanya dalam waktu 30-90 hari.

Pada saat RAD diimplementasikan, maka para pemakai bisa menjadi bagian dari keseluruhan proses pengembangan sistem dengan bertindak sebagai pengambil keputusan pada setiap tahapan pengembangan. RAD bisa menghasilkan suatu sistem dengan cepat karena sistem yang dikembangkan dapat memenuhi keinginan dari para pemakai sehingga dapat mengurangi waktu untuk pengembangan ulang setelah tahap implementasi (Noertjahyana, 2002). ${ }^{[8]}$

Ada 4 tahapan yang harus dilakukan pada metodologi RAD yaitu analisis persyaratan, analisis modeling, desain modeling dan konstruksi :

\section{a) Analisis Persyaratan}

Tahap ini bertujuan untuk mengidentifikasi kebutuhan pengguna, spesifikasi sistem melalui observasi dan pengumpulan data yang dilakukan terhadap stakeholders, sehingga aplikasi yang akan dibuat akan sesuai dengan yang dibutuhkan oleh pengguna.

\section{b) Analisis Modeling}

Tujuan dari fase analisis modeling adalah menganalisa semua kegiatan dalam arsitektur sistem secara keseluruhan dengan melibatkan identifikasi dan deskripsi abstraksi sistem perangkat lunak yang mendasar dan hubungan-hubungannya. Selain itu, analisis modeling juga bertujuan untuk meningkatkan pemahaman terhadap permasalahan tanpa mempertimbangkan solusi teknis. Hasil akhir dari analisis modeling yaitu diagram model logis sistem yang sedang berjalan. ${ }^{[8]}$

c) Desain Modelling

Tujuan dari fase desain modeling yaitu melakukan perancangan sistem berdasarkan analisis yang telah dilakukan sebelumnya. Tahap analisis dan desain mengalami perulangan hingga diperoleh rancangan sistem yang benar-benar memenuhi kebutuhan. Selain itu, fase ini juga bertujuan untuk memberikan spesifikasi yang jelas dan lengkap kepada programmer dan teknisi. Hasil akhir dari fase ini yaitu basis data, antarmuka, dan spesifikasi desain.

\section{d) Konstruksi}

Tujuan dari fase konstruksi adalah untuk menunjukkan platform, hardware dan software yang digunakan serta batasan dalam implementasi, serta menguji performansi prototipe perangkat lunak yang telah dibangun agar dapat diketahui apakah prototipe 
tersebut telah sesuai dengan spesifikasi analisis dan perancangan yang telah diidentifikasi sebelumnya.

\section{HASIL DAN PEMBAHASAN}

A. Tahap Analisis Persyaratan

Fase Analisis Persyaratan merupakan proses melakukan pengumpulan data atau bahan dan mengidentifikasi layanan, batasan, dan obyektivitas dari pengumpulan data yang dilakukan.

Hasil dari proses ini berupa laporan penelitian dari pengembangan aplikasi, analisis spesifikasi awal, analisis persyaratan user dan sistem, dan informasi fitur pada aplikasi.

\section{a) Rencana Kerja}

Langkah pertama dalam pembuatan aplikasi ini yaitu menyusun rencana kerja. Ini berguna agar setiap proses yang dilakukan dalam pembuatan aplikasi jelas dan terstruktur. Rencana kerja pembuatan aplikasi ini dapat dilihat pada Gambar 2.

b) Manajemen Resiko

Dalam setiap proyek, tentu saja diperhadapkan dengan berbagai macam resiko. Tabel 1 adalah resiko yang mungkin terjadi dalam pengembangan aplikasi.

c) Spesifikasi Pengguna

Langkah ini merupakan langkah mengidentifikasi dan menetapkan kebutuhan-kebutuhan pengguna. Hasil dari daftar pengguna beserta tugasnya dapat dilihat pada Tabel 2 .

B. Tahap Analisis Modelling

Fase berikutnya adalah fase analisis modeling yang bertujuan menganalisis semua kegiatan dalam arsitektur sistem secara keseluruhan dengan cara identifikasi dan abstraksi sistem yang mendasar

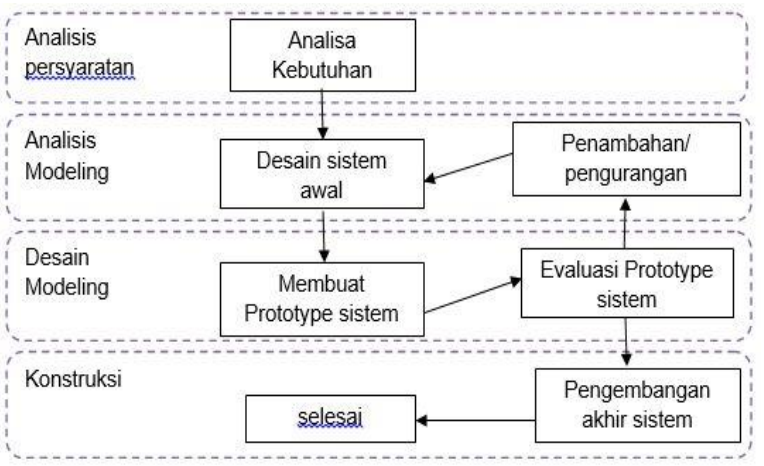

Gambar 2. Rencana Kerja
Proses yang dilakukan dimulai dari mengidentifikasi aktor dan use case dengan merancang aplikasi yang akan dikembangkan, menggambarkan aliran control untuk mengetahui hubungan aktor dan objek, menggambarkan komunikasi antar objek dan aktor, menggambarkan perubahan keadaan suatu objek pada aplikasi kelas tertentu, memodelkan prilaku use case serta objek pada aplikasi dan menggambarkan perubahan suatu objek pada kelas tertentu.

a) Mengidentifikasi Pelaku Bisnis

Identifikasi para pelaku bisnis atau para pengguna aplikasi merupakan salah satu proses penting dalam pembuatan aplikasi sehingga para programmer tau siapa saja yang akan menggunakan aplikasi yang akan dibuat. Tabel 3 merupakan daftar pelaku bisnis yang ada pada aplikasi yang akan di buat.

b) Use Case Diagram

Use case diagram aplikasi pemantauan trafik lalu lintas menggunakan GPS smartphone dapat dilihat pada gambar 3 .

Dari use case ini maka dapat digambarkan aplikasi pemantauan trafik lalu lintas menggunakan GPS smartphone memiliki dua actor yaitu User sebagai pengguna aplikasi di smarthphone dan admin yang menggunakan web browser unutk mengakses database yang dikirmkan oleh $u$ ser.

Tabel 1. Manajemen Resiko

\begin{tabular}{|l|l|l|l|}
\hline \multicolumn{1}{|c|}{ Risk } & \multicolumn{1}{c|}{ Contigency } & \multicolumn{1}{c|}{ Cause } & \multicolumn{1}{c|}{ Effect } \\
\hline $\begin{array}{l}\text { Perubahan } \\
\text { jadwal. }\end{array}$ & $\begin{array}{l}\text { Penyesuaian } \\
\text { jadwal } \\
\text { kembali. }\end{array}$ & $\begin{array}{l}\text { Keterlamba } \\
\text { tan. }\end{array}$ & $\begin{array}{l}\text { Waktu lebih } \\
\text { lama. }\end{array}$ \\
\hline $\begin{array}{l}\text { Kesalahan } \\
\text { pemrograman }\end{array}$ & $\begin{array}{l}\text { Perbaikan } \\
\text { kesalahan } \\
\text { pemrograman. }\end{array}$ & $\begin{array}{l}\text { Ketidak- } \\
\text { telitian. }\end{array}$ & $\begin{array}{l}\text { Keterlambata } \\
\text { n dan } \\
\text { performa } \\
\text { yang tidak } \\
\text { maksimal. }\end{array}$ \\
\hline $\begin{array}{l}\text { Perubahan } \\
\text { persyaratan } \\
\text { pengguna. }\end{array}$ & $\begin{array}{l}\text { Pemrograman } \\
\text { kembali. }\end{array}$ & $\begin{array}{l}\text { Keinginan } \\
\text { user } \text { yang } \\
\text { berubah- } \\
\text { ubah. }\end{array}$ & $\begin{array}{l}\text { Keterlambata } \\
\text { n dan } \\
\text { performa } \\
\text { program yang } \\
\text { tidak } \\
\text { maksimal. }\end{array}$ \\
\hline $\begin{array}{l}\text { Kesalahan } \\
\text { analisis } \\
\text { sistem. }\end{array}$ & $\begin{array}{l}\text { Analisis } \\
\text { kembali dan } \\
\text { terjadi } \\
\text { perombakkan } \\
\text { desain. }\end{array}$ & $\begin{array}{l}\text { Keinginan } \\
\text { user } \text { yang } \\
\text { tidak } \\
\text { teridentifik } \\
\text { asi dengan } \\
\text { baik. }\end{array}$ & $\begin{array}{l}\text { Perubahan } \\
\text { fitur. }\end{array}$ \\
\hline
\end{tabular}


Tabel 2. Daftar Pengguna dan Tanggung Jawabnya

\begin{tabular}{|c|c|}
\hline Pengguna & Tugas dan Tanggung Jawab \\
\hline User & $\begin{array}{l}\text { - Mengetahui posisi awalnya melalui } \\
\text { latitude dan longitude. } \\
\text { - Dapat memberikan laporan posisi } \\
\text { secara real time. } \\
\text { - Dapat memberikan laporan kecepatan } \\
\text { perpindahan posisi. } \\
\text { - Dapat memberikan laporan waktu } \\
\text { perpindahan posisi. }\end{array}$ \\
\hline Admin & $\begin{array}{l}\text { - Melihat plat nomor kendaraan. } \\
\text { - Melihat data latitude dan longitude } \\
\text { - } \text { Mari user secara real time } \\
\text { - Melihat posisi kepadatan } \text { user } \\
\text { user }\end{array}$ \\
\hline
\end{tabular}

C. Tahap Desain Modeling

Pada fase desain modeling aplikasi pemantauan trafik lalu lintas menggunakan GPS smartphone ini, dikembangkan berdasarkan analisis yang dilakukan pada fase analisis modeling sebelumnya. Pada tahapan analisis dan desain modeling mengalami perulangan bertujuan untuk mendapatkan hasil perancangan sistem yang benar-benar memenuhi kebutuhan. Hasil dari fase ini adalah basis data, antarmuka dan spesifikasi desain.

a) Mengidentifikasi struktur objek dan relasinya Pada gambar 4 merupakan Entity Relationship Diagram (ERD) dari aplikasi. Entity dari aplikasi ini adalah gps, yang mempunyai atribut berupa Primari Key id, nama, longitude, latitude, speed, dan waktu.

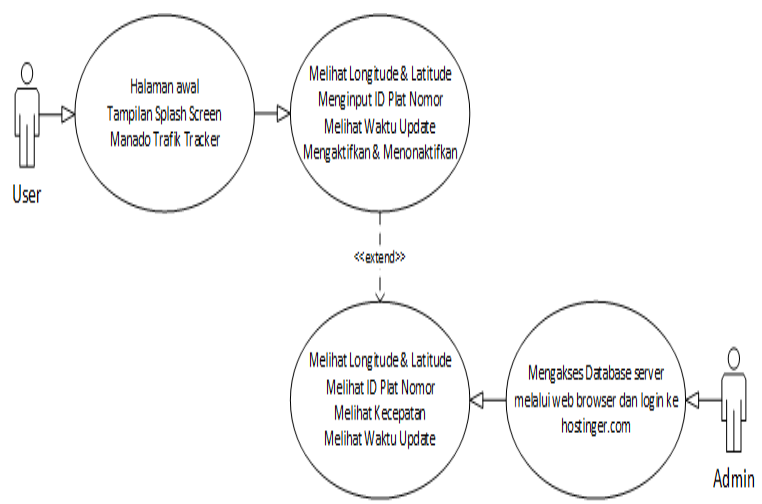

Gambar 3. Use Case Aplikasi Monitoring
Tabel 3. Daftar Aktor Beserta Tugas dan Tanggung Jawabnya

\begin{tabular}{|c|c|}
\hline Aktor & Tugas dan Tanggung Jawab \\
\hline $\begin{array}{l}\text { Admin } \\
\text { (Server side) }\end{array}$ & $\begin{array}{l}\text { 1. Mengatur database berupa } \\
\text { edit data, dan hapus data } \\
\text { Melihat data yang telah di } \\
\text { kirim user ke database } \\
\text { server. }\end{array}$ \\
\hline $\begin{array}{l}\text { User } \\
(\text { Android } \\
\text { App - Client } \\
\text { side })\end{array}$ & $\begin{array}{l}\text { Memasukan Id Plat nomor } \\
\text { Kendaraan }\end{array}$ \\
\hline
\end{tabular}

D. Tahap Konstruksi

Fase konstruksi ini merupakan tahapan pembuatan aplikasi yang mengacu pada tahapan sebelumnya dimana untuk menunjukan platform, hardware dan software yang digunakan serta batasan dalam implementasi dan menguji performansi dari aplikasi yang akan dikembangkan.

a) Implementasi Antar Muka

Berikut ini adalah penjelasan mengenai penerapan antarmuka aplikasi pemantauan trafik lalu lintas menggunakan GPS smartphone, pertama-tama user menjalankan aplikasi yang sudah diinstall pada perangkat android.

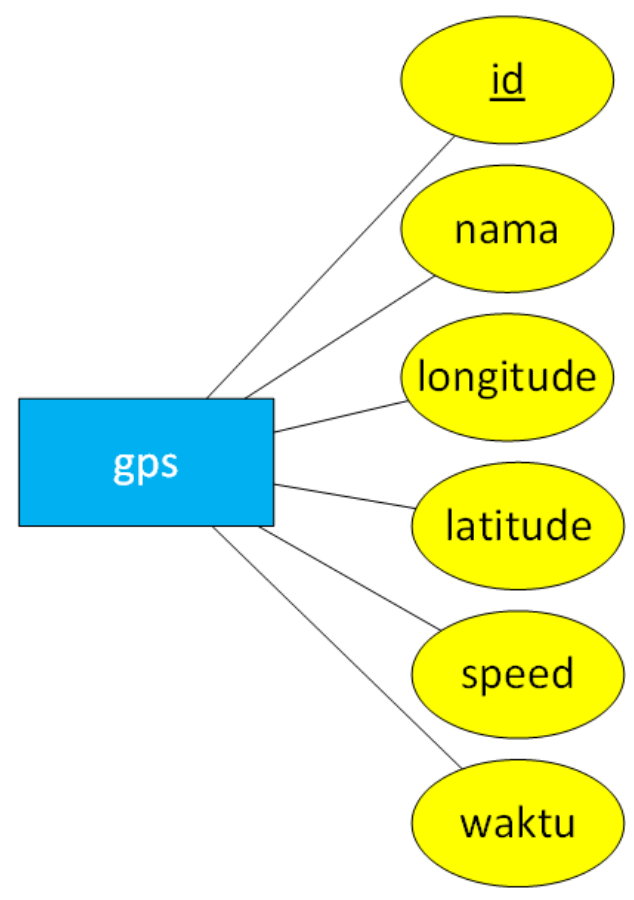

Gambar 4. Entity Relationship Diagram (ERD) 
Jika kita menginstal aplikasi pemantauan trafik lalu lintas menggunakan GPS smartphone pada perangkat android, maka secara otomatis icon aplikasi akan muncul pada menu android, seperti terlihat pada gambar 5 .

- Tampilan Awal

Pada saat aplikasi dijalankan, tampilan pada gambar 6 merupakan splashscreen dari aplikasi, akan terlihat sebagai tampilan awal saat masuk aplikasi dan juga sebagai logo aplikasi.

- Tampilan Utama

Saat aplikasi android dibuka maka akan masuk pada tampilan utama seperti pada gambar 7. User dapat mengisi id kendaraan dan melihat longitude, latitude, kecepatan, tanggal dan waktu update kendaraan, timer waktu dan satelit.

\section{E. Pengujian Sistem}

Kasus pengujian dapat dilihat pada table 5, dimana tujuan dari pengujiaan ini yaitu:

1. Pengujian sistem dilakukan untuk mengecek apakah persyaratan pengguna sudah terpenuhi.

2. Untuk memastikan tidak terjadi error dalam sistem.

3. Untuk mengetahui apa yang akan terjadi pada sistem apabila dimasukkan data.

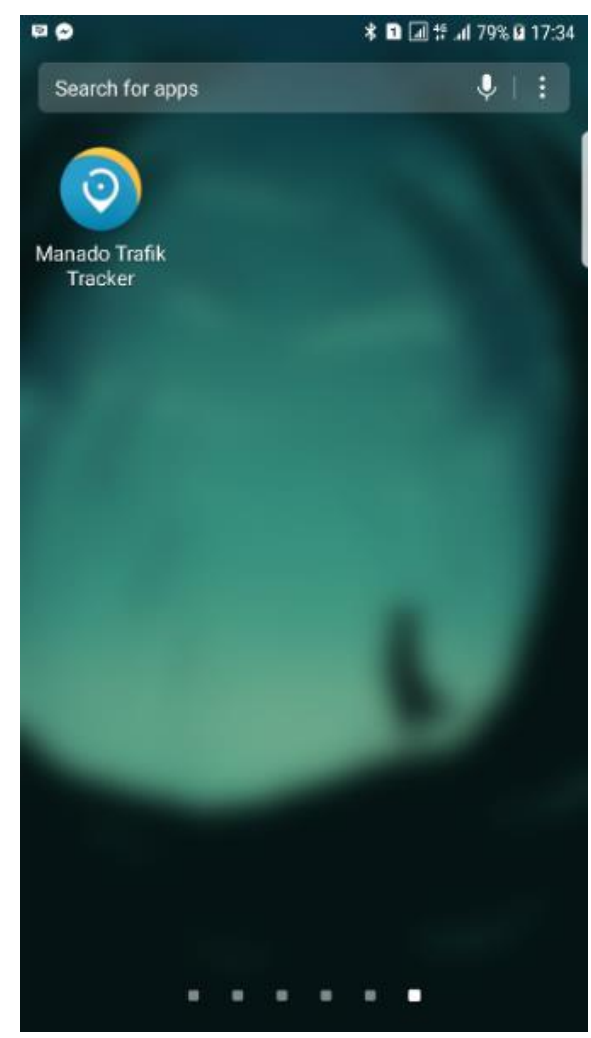

Gambar 5. Icon Aplikasi

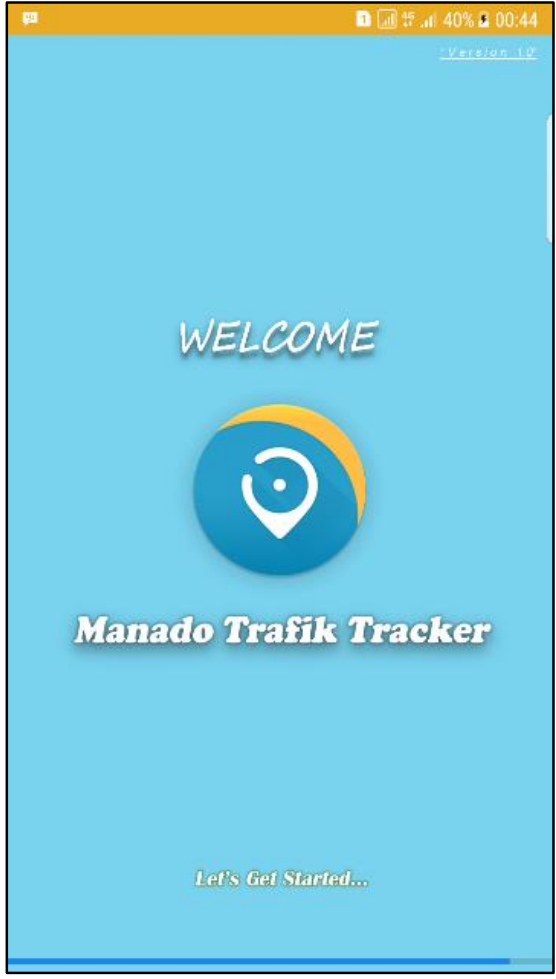

Gambar 6. Tampilan Awal Masuk Aplikasi

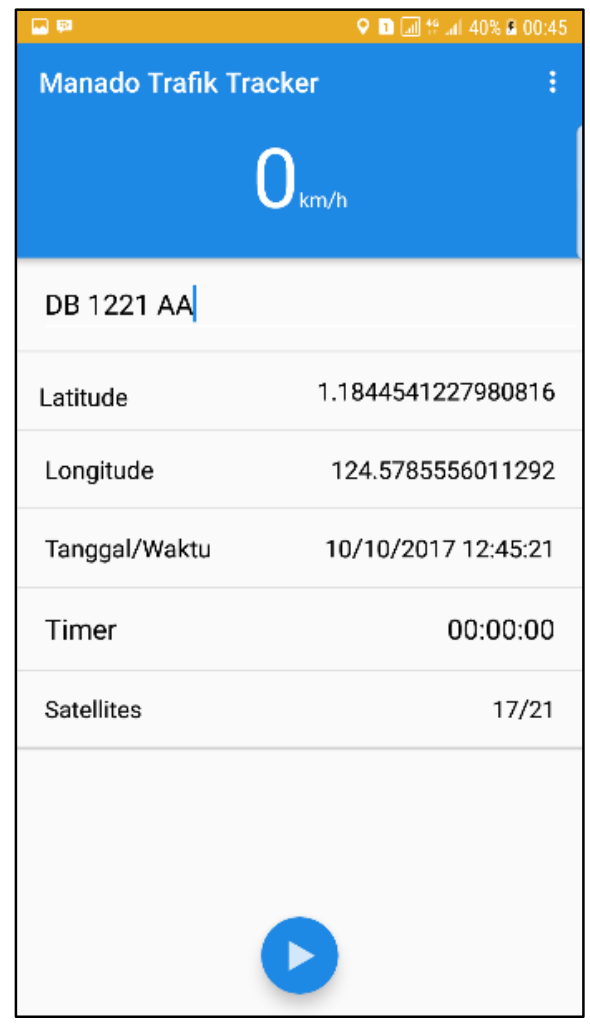

Gambar 7. Tampilan Utama 
Kriteria pengujian sistem secara umum yaitu aplikasi dapat dijalankan dengan baik dan tidak terjadi error. Beberapa kriteria yang menjadi patokan keberhasilan sistem ini yaitu sebagai berikut:

1. Aplikasi yang dikembangkan sesuai dengan hasil analisa dan perancangan yang dilakukan.

2. Fungsi atau prosedur yang diimplementasikan berjalan dengan baik.

3. Fitur - fitur dalam aplikasi ini dapat menjadi sarana komunikasi antar user dan operator, dimana laporan yang diberikan user dapat dilihat oleh operator bahkan oleh user yang lain.

Pada gambar 8 merupakan screenshot data csv yang telah di export dari data sql yang dihasilkan pada pengujian aplikasi, yang nantinya akan diolah lagi untuk mengetahui kecepatan rata-rata kendaraan. dimana data diambil secara realtime menggunakan 30 user kendaraan mobil dan 30 user kendaraan motor.

Aplikasi yang dibangun dari tools khusus android mulai khawatir dengan produksi terbaru android studio yang merupakan lingkungan pengembangan terpadu - Integrated Development Environment (IDE) untuk pengembangan aplikasi Android, berdasarkan IntelliJ IDEA .. Tampilan yang lebih menarik serta cara penggunaan yang lebih simple dan mudah dipahami membuat penulis memakai tools ini untuk membuat aplikasi pemantauan trafik lalu lintas menggunakan GPS smartphone.

Maka dari itu, penyajian informasi yang disediakan aplikasi ini mudah diterima bagi masyarakat dalam memantau trafik lalu lintas menggunakan GPS smartphone.

\section{Tabel 5. Tabel Pengujian}

\begin{tabular}{|l|}
\hline Titik Pemeriksaan \\
\hline Testing menjalankan aplikasi \\
\hline $\begin{array}{l}\text { Apakah halaman awal dan halaman utama akan } \\
\text { ditampilkan oleh sistem? }\end{array}$ \\
\hline Testing fungsi mengisi id kendaraan \\
\hline Apakah data yang dimasukan diterima oleh sistem? \\
\hline Apakah sistem dapat menyimpan data di database? \\
\hline Testing fungsi berpindah tempat \\
\hline $\begin{array}{l}\text { Apakah sistem dapat menampilkan perubahan posisi } \\
\text { gps? }\end{array}$ \\
\hline Apakah sistem menyimpan data posisi gps? \\
\hline $\begin{array}{l}\text { Apakah sistem dapat menampilkan kecepatan } \\
\text { kendaraan? }\end{array}$ \\
\hline Apakah sistem menyimpan kecepatan kendaraan? \\
\hline $\begin{array}{l}\text { Apakah sistem dapat menampilkan waktu update } \\
\text { kendaraan? }\end{array}$ \\
\hline $\begin{array}{l}\text { Apakah sistem menyimpan waktu update } \\
\text { kendaraan? }\end{array}$ \\
\hline
\end{tabular}

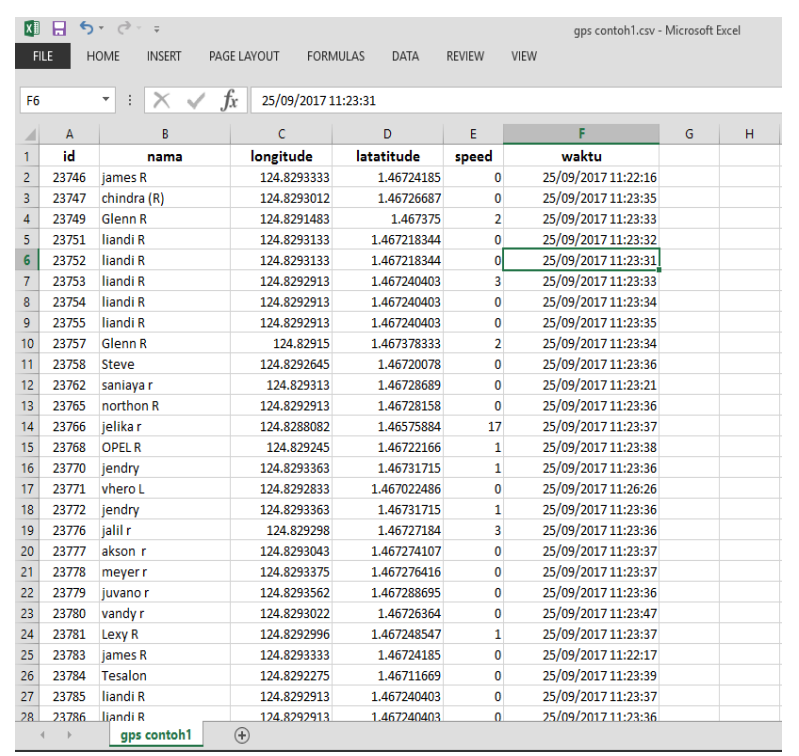

Gambar 8. Data CSV yang dihasilkan

\section{KESIMPULAN DAN SARAN}

\section{A. Kesimpulan}

Berdasarkan hasil pengujian sistem yang telah dilakukan, aplikasi pemantauan trafik lalu lintas ini memiliki karakteristik-karakteristik sebagai berikut:

1. Aplikasi hanya dapat dijalankan jika tersedia akses paket data dari provider yang digunakan oleh user.

2. Kecepatan Internet mempengaruhi dalam penggunaan aplikasi ini.

3. Sinyal GPS mempengaruhi dalam penggunaan aplikasi ini

B. Saran

Untuk pengembangan lebih lanjut aplikasi pemantauan trafik lalu lintas dapat memperlihatkan trafik lalu lintas dalam bentuk map dan dapat dibuatkan versi aplikasi dilingkungan system operasi mobile selain android.

\section{DAFTAR PUSTAKA}

[1] Anton Supraitno, Hindarto. 2015. Monitoring Kendaraan Ekspedisi Dengan Sistem Mobiles To Mobile. Universitas Muhammadiyah Sidoarjo.

[2] Aris, Azhar. 2012. Analisis Dampak Sosial Ekonomi Pengguna Jalan Akibat Kemacetan Lalu lintas (Studi Kasus Area Universitas Brawijaya Malang). Malang: Universitas Brawijaya.

[3] Julian Muhammad Iqbal, dkk. 2016. Implementasi Undang-Undang Nomor 22 Tahun 2009 Tentang Lalu Lintas Dan Angkutan Jalan 
Dalam Pembinaan Anggota Club Beat Borneo Community Di Kota Samarinda (Jurnal). Administrative Reform, Volume 4, Nomor 3, 2016.

[4] Wahono S. Romi. 2014. Pengertian Android \& Pengertian Aplikasi, [Online]. Tersedia : www.ilmukomputer.com [Diakses tanggal 20 November 2016].

[5] Kasenda M. Lorenzo, Sentinuwo R. Steven, Tulenan Virginia. (2016). Sistem Monitoring Kognitif, Afektif dan Psikomotorik Siswa Berbasis Android. Manado: e-jurnal Teknik Informatika 2016.

[6] Asep Husni Mubarok, dkk. Pembangunan Aplikasi Traffic Report System Kendaraan Bermotor Berbasis Android. Universitas Siliwangi Tasikmalaya.

[7] I Made Oka Widyantara, dkk. 2015. Penerapan Teknologi GPS Tracker Untuk Identifikasi Kondisi Traffik Jalan Raya (Jurnal). Teknologi Elektro, Vol.14, No.1, Januari-Juni 2015.

[8] Tim Pengembang Portal Resmi UNSRAT. 2015. Laporan Akhir RAD Pembangunan Portal Resmi Universitas Sam Ratulangi Manado.

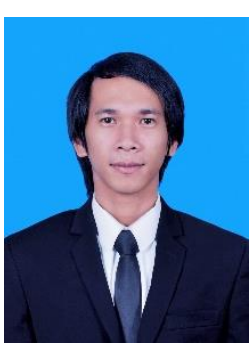

Sekilas dari penulis dengan nama lengkap Nofli Kristofel Staal, lahir di Kwandang, Kabupaten Gorontalo Utara, Provinsi Gorontalo. Anak ke-2 dari 3 bersaudara dengan pendidikan Sekolah Dasar Negeri 3 Amurang. Penulis lalu melanjutkan ke Sekolah Menengah Pertama Negeri 1 Tombasian. Lalu ke SMA Negeri 1 Tombasian. Pada tahun 2011 melanjutkan ke Perguruan Tinggi di Universitas Sam Ratulangi dengan mengambil Jurusan Teknik Informatika. Pada Tahun 2016 bulan Mei, penulis membuat Skripsi demi memenuhi syarat Sarjana (S1) dengan penelitian berjudul Rancang Bangun Aplikasi Pemantauan Trafik Lalu Lintas Menggunakan GPS Smartphone yang dibimbing oleh dua dosen pembimbing yaitu Dr. Eng. Steven R. Sentinuwo, ST., MTI dan Alwin M. Sambul, ST., M.Eng., Ph.D sehingga pada tanggal 30 Oktober 2017 penulis resmi lulus di Teknik Informatika Universitas Sam Ratulangi Manado menyandang gelar sarjana komputer dengan predikat sangat memuaskan. 